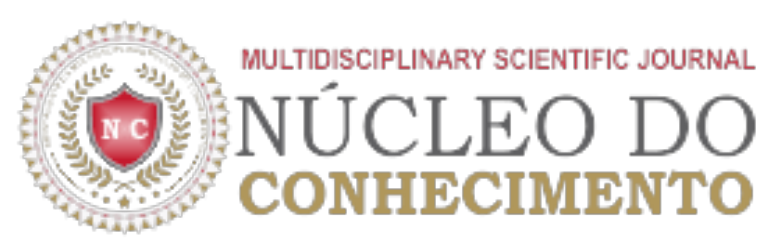

\title{
O Impacto da Regulação Econômica no Mercado de Telecomunicações Brasileiro: O Segmento de Telefonia Móvel
}

PORTELLA, Anderson Gonçalves ${ }^{[1]}$

PORTELLA, Anderson Gonçalves. O Impacto da Regulação Econômica no Mercado de Telecomunicações Brasileiro: O Segmento de Telefonia Móvel. Revista Científica Multidisciplinar Núcleo do Conhecimento. Ano 03, Ed. 06, Vol. 06, pp. 80-107, Junho de 2018. ISSN:2448-0959

\section{Resumo}

O presente artigo tem como objetivo demonstrar os resultados da intervenção do Estado brasileiro no período pós-privatização com a implantação do modelo regulatório de telecomunicações, especificamente no segmento de telefonia móvel brasileiro. O trabalho aborda inicialmente os fundamentos da Teoria de Regulação, destacando as escolas européia e americana, este último o modelo básico utilizado no caso brasileiro. Sob esta perspectiva, o texto estuda, analisa e avalia o modelo de regulação implantado no mercado de telecomunicações e sua evolução, discutindo a adequação do modelo e sua consequente eficiência no alcance dos objetivos almejados inicialmente. As considerações deste trabalho permitem concluir que o modelo regulatório implantado no Brasil apresentou-se eficaz na medida em que permitiu diversos ganhos de produtividade e impulsionou o desenvolvimento socioeconômico. Apresentou, contudo, falhas decorrentes das características intrínsecas do mercado brasileiro, permitindo a captura da reguladora ANATEL pelo agente Estado, e sujeitando as decisões de cunho técnico a eventuais interesses políticos.

Palavras-chave: Regulação Econômica, Mercado de Telecomunicações, Captura do Regulador, Escolha Pública.

\section{Introdução}

O objetivo deste artigo é abordar o processo de regulação econômica ocorrido na implantação das privatizações iniciadas na década de 90 , que deram início às transformações nas telecomunicações brasileiras e que afetaram principalmente os segmentos de telefonia móvel e fixa. Setores estes em que o Estado atua com o objetivo fundamental de estimular a competição e buscar a melhoria da infraestrutura de telecomunicações. 
Como, em geral, os setores de infraestrutura são caracteristicamente marcados pela tendência ao monopólio natural, torna-se necessária a criação de um sistema regulatório, caso o mercado não seja contestável, para acompanhar o funcionamento e os resultados almejados para a sociedade e para economia. Desta forma, a necessidade de um sistema regulador eficaz avançou à medida que o processo de privatização alcançou a prestação de serviços de utilidade pública (public utilities) como é o caso do mercado de telecomunicações, objeto do presente estudo.

Do ponto de vista da regulação econômica, Joskow (1981, p. 36, apud Fiani, 2005) argumenta que as entidades de regulação setorial intervêm visando corrigir "falhas de mercado", sendo criadas num contexto em que a economia necessitava expandir os serviços de infraestrutura, essenciais para o desenvolvimento econômico que o governo não foi capaz de suprir adequadamente.

Stigler (1971), por outro lado, argumenta que a regulamentação nem sempre é o caminho mais eficiente, pois "o monopólio natural não conduz a uma situação [necessariamente] ineficiente, pois haveria mecanismos que introduziriam a competição mesmo sob o monopólio.” (Giambiagi e Além, 2001).

Peltzman (1976, p. 237 apud Fiani, 2005) argumenta ainda que a regulamentação apresenta falhas inerentes do processo de sua criação, e que ela seria incapaz de conduzir aos resultados desejados pois estaria sujeita de um lado a pressões dos produtores (concessionárias), e de outro, a pressões políticas. Cabe aqui ressaltar que do lado político a pressão interfere na eficácia das ações regulatórias, sendo que a aplicação destas políticas é inerente ao poder concedente.

Os usuários por sua vez também pressionam por melhorias constantes na prestação do serviço.

\section{Objetivo}

O foco deste trabalho é analisar o modelo de regulação do mercado de telefonia móvel brasileiro, destacando suas eventuais virtudes e possíveis falhas. De forma mais específica, visa:

1. Estudar e analisar a estrutura de telecomunicações apresentada no período pré-privatização, ou seja, o monopólio;

2. Apresentar a evolução do processo de regulação econômica, e o modelo implantado no Brasil;

3. Expor a evolução do mercado de telecomunicações brasileiro, através do segmento de telefonia móvel e fixa desde o período da privatização até o ano de 2010 e, quando possível, até meados de 2011 ;

4. Identificar as vantagens e desvantagens do modelo de regulação econômica implantado no mercado de telecomunicações brasileiro (segmento de telefonia móvel e fixa).

A relevância do tema está em sua complexidade, pois a interferência do governo nas decisões dos agentes econômicos visa corrigir distorções que não puderam ser resolvidas como explicado no teorema de Coase $^{[2]}$ - no qual os agentes econômicos privados, num contexto livre de custos entre as transações, podem solucionar seus problemas entre si - mas pode gerar outros problemas que classificamos como "falhas de governo".

Observa-se que, via de regra, "soluções" são quase sempre ilusões, onde, ao se comparar as alternativas apresentadas, esbarramos em "trade-offs", e em "incentivos" que são gerados pela interferência do estado 
regulador. Há ainda "efeitos sistêmicos" que podem ser indiretos e/ou de mais longo prazo, gerando efeitos (que explicam melhor o quadro quando o mercado é regulado) e ações (que são consequências da adaptação do mercado à regulamentação criada) não pretendidos pelos agentes.

Um argumento novo que está sendo considerado pelos teóricos regulacionistas, refere-se ao avanço das tecnologias (inovações tecnológicas), que afetam significativamente os custos mínimos, assim como a escala ótima de produção, o que por si só já afetaria em muitos casos a produção a ponto de eliminar os monopólios naturais tão indesejáveis.

Obviamente que a total desregulamentação não pressupõe a existência de um quadro de "concorrência perfeita", mas sim a proximidade de um oligopólio, que mais uma vez, devido ao notório interesse público da prestação destes serviços não dispensa a existência de uma regulação (com clara regulamentação das atividades).

A regulação econômica deriva da análise do comportamento dos mercados, onde a defesa da concorrência tem por finalidade garantir a existência de condições para competição, a qual, por princípio, levaria à maior eficiência econômica como resultado do funcionamento do mercado.

Os instrumentos de regulação têm sido empregados em setores dedicados à prestação de serviços públicos, os quais são prestados por empresas privadas autorizadas ou permissionárias.

Esta pesquisa pode ser classificada de bibliográfica, permitindo desta forma deduzir conclusões através da observação dos dados coletados (Lakatos e Marconi, 1987, p. 66) e foi feita através do levantamento, seleção e documentação da bibliografia relevante já publicada sobre o assunto em livros, enciclopédias, revistas, jornais, folhetos, boletins, monografias, teses, dissertações e etc.

A coleta dos dados foi realizada em sua grande maioria a partir do farto material disponibilizado pela ANATEL, sendo que também foram utilizados dados provenientes de sites especializados em telecomunicações citados na bibliografia.

Com os dados obtidos, mensurou-se os ganhos relacionados ao modelo de regulação adotado, bem como as possíveis falhas observadas no modelo, as inovações tecnológicas geradas, a evolução de alguns dos indicadores antes e depois da desestatização do setor e, finalmente, o impacto da regulação econômica no setor de infraestrutura de telecomunicações.

Realizou-se desta forma um exercício de reflexão sobre a evolução do mercado de telecomunicações, de forma que se possa medir a eficácia, relacionando o resultado obtido com o resultado esperado (realizado $\mathrm{x}$ metas). Tendo em vista o alto grau de convergência, tecnologia e avanços já alcançados pelo setor, se apresenta algumas recomendações que tem como objetivo alavancar políticas pró-competitivas no segmento estudado.

\section{Determinantes da regulação: o monopólio natural}

Conforme descrito por VARIAN (2003), o monopólio natural ocorre quando há grandes custos fixos e custos marginais pequenos, sendo que ao operar onde o preço se iguala ao custo marginal e, alcançar um nível eficiente de produção, ele não consegue cobrir seus custos e, quando é obrigado a produzir em um 
nível em que o preço se iguale ao custo médio, ele cobre seus custos, mas produz muito pouco em relação à quantidade eficiente.

Desta forma, em monopólio natural percebe-se que o mercado não comporta a existência de mais de uma empresa operando com eficiência. Isto decorre, fundamentalmente, da subaditividade da função custo nestas condições, pois "os custos serão menores se produzirmos uma dada quantidade " $\mathrm{x}$ " do produto em uma única firma do que em duas”. (Fiani e Pinto Jr, 2002).

Apesar dessa vantagem em termos de eficiência produtiva, o preço ótimo do ponto de vista da sociedade (custo marginal), é inferior ao preço de equilíbrio do monopolista para obtenção do lucro normal que cobriria o seu custo médio. Esse fato ocorre devido às economias de escala que fazem com que o custo médio seja declinante, e que o custo marginal seja inferior ao médio, impedindo a ocorrência da solução ótima encontrada em situação de concorrência perfeita.

As indústrias de infraestrutura são exemplos clássicos de monopólio natural, como no caso brasileiro dos setores de energia elétrica e telecomunicações, que na sua origem foram desenvolvidos com uma estrutura de monopólio de propriedade estatal. Tal fato ocorreu devido a um consenso de que esta estrutura seria a mais eficaz para desenvolver tais setores, e que os altos investimentos iniciais seriam impeditivos para a atuação do setor privado, além da execução de projetos que envolveriam longo prazo de maturação.

A entrada de novas empresas corresponde à remoção das barreiras à entrada nos setores de infraestrutura, o que não impedirá que ocorram ineficiências produtivas caso a exploração das economias de escala e/ou escopo esteja sendo obtida através de uma estrutura de preços de forma cartelizada e discriminatória por parte do monopolista

A presença de novos entrantes, assim como a remoção de barreiras à entrada deverá ocorrer nos segmentos onde os preços estiverem acima dos custos médios, o que compromete a eficiência produtiva e/ou a capacidade do monopolista de financiar outros objetivos não econômicos, como a universalização de serviços prestados.

Para que esta situação não ocorra, torna-se necessário que haja outra forma de financiamento dos objetivos, através de subsídios diretos ou indiretos por exemplo. No entanto, a eficácia econômica poderá vir a ser atingida através de um modelo pró-competitivo como meio de cercear os limites do monopólio natural.

É importante ressaltar que o período de transição entre o monopólio estatal brasileiro e um modelo próconcorrência impôs a necessidade de monitoração constante das condutas empresariais, além de conformação das novas estruturas de mercado mais competitivas nos segmentos abertos, buscando o desempenho eficiente.

\section{Mudanças da base tecnológica e as novas abordagens de regulação que interferem no monopólio natural}

A questão tecnológica proporcionou nova visão sobre o monopólio natural de telecomunicações a partir da década de 70, com o avanço da tecnologia óptico-digital substituindo o modelo eletromecânico, que segundo Dosi (1982) permitiu, através de um conjunto limitado de alternativas tecnológicas disponíveis, especular sobre o desenvolvimento das tecnologias futuras. 
A possibilidade de introdução das novas tecnologias abriu oportunidade para o aumento da competição e para aceleração do progresso técnico.

Segundo Marshall discutiu no livro IV dos Principles of Economics, as empresas desenvolvem-se ao longo de um ciclo de vida, e a partir de determinado momento, seu gigantismo não evolui em conjunto com as necessidades permanentes de mudança do mercado. O resultado é o envelhecimento das boas soluções criadas no passado e a decadência da empresa.

O monopólio estatal das telecomunicações passou por este ciclo, e perdeu a vantagem da economia de escala em um universo que já estava em constante mudança, e cada vez mais necessitava de economias de escopo para sobreviver.

A partir da década de 80 ocorreram mudanças significativas, tanto no aspecto da organização econômica, quanto no regime tecnológico. Desde então o setor encaminhou-se para uma crescente desregulamentação do setor, e para a privatização das empresas antes estatais, com consequente separação mais clara entre as empresas de rede e as prestadoras de serviço.

A “desregulamentação" também possui defensores que argumentam que bastaria que a concessão fosse renovada periodicamente através de leilão.

A Teoria dos Custos de Transação (TCT) de Coase demonstra que o argumento é falho na medida em que a renovação necessitaria de um prazo a ser definido, que gera por si só "trade-offs". Sendo um prazo curto não estimularia o concessionário a realizar investimentos com longo prazo de maturação.

Isso ocorre devido à incerteza de que ao transferir essa concessão para outra empresa ela receba o retorno pelos seus investimentos adequados.

Ainda segundo a TCT, se o prazo de renovação for longo demais, haverá o custo para amortização/recuperação de seus investimentos, que implicaria em complexas cláusulas condicionais que antecipassem todas as circunstâncias e cenários relevantes no futuro.

\section{Evolução do processo de regulação}

Nos anos 80, do século passado, duas formas de regulação se destacaram nos EUA tendo como interesse básico a defesa do interesse público. A primeira foi centrada na regulamentação através do arcabouço jurídico-institucional norte-americano, sendo apoiada nas tradições e na jurisprudência para arbitragens dos conflitos entre diferentes agentes.

A segunda forma foi desenvolvida na Europa a partir da década de 1940 na qual o Estado assumia a responsabilidade de planejamento, operação, coordenação e gestão da infraestrutura econômica. Sob o ponto de vista jurídico-institucional foram definidas propriedades de serviço público e do ponto de vista da estrutura industrial, o modelo das indústrias caracterizou-se pela constituição de grandes empresas estatais dispondo de monopólios territoriais sendo integrados de forma vertical. A regulação europeia tem uma visão mais preventiva e mais interveniente.

Tradicionalmente na regulação americana a regulação da concorrência é baseada nas leis antitruste, sendo 
o monopólio a exceção e a concorrência a regra.

Os Estados Unidos sofreram clara influência dos entes autônomos criados na Inglaterra em 1834 que visavam cumprir medidas definidas em lei pelo Parlamento. A cada lei que disciplinasse um assunto de relevo, um ente era criado para aplicar a lei. Em 1887, nos Estados Unidos, surgiam as agencies para regulação de atividades, imposição de deveres na matéria e aplicação de sanções. A visão norteamericana de regulação é menos interveniente e mais punitiva (cartel é crime).

A ideia de regulação no Brasil não é nova, ou totalmente desconhecida, pois diversas iniciativas criaram órgãos e entidades reguladoras, embora não tenham sido denominadas agências reguladoras, tais como Comissariado de Alimentação Pública (1918), Instituto de Defesa Permanente do Café - IBC (1923), o Instituto do Álcool e do Açúcar - IAA (1933), o Instituto Nacional do Mate (1938), o Instituto Nacional do Sal (1940) e o Instituto Nacional do Pinho (1941).

O processo de regulação econômica no Brasil tomou importância na década de 90 com o advento do processo de privatização que criou a necessidade de diferenciação entre o poder concedente, e o poder regulador, embora em alguns casos os papéis sejam exercidos conjuntamente. Após a concessão pelo Estado, as empresas prestadoras de serviço ficaram subordinadas ao regulador.

As prestadoras de serviço compreendem uma indústria, onde existe uma estrutura inicial primária que possui, por exemplo, barreiras de entrada, o poder do comprador e o do fornecedor. Quanto maior o grau de inovações, isto é, mudanças no "espaço econômico" no qual as empresas operam (mudanças nos produtos, nos processos produtivos, nas fontes de matérias-primas, nas formas de organização produtiva, ou nos próprios mercados, inclusive em termos geográficos), maiores serão as vantagens competitivas, economias de escala e de escopo.

Historicamente o Brasil avançou na aplicação de leis antitruste no período de 1995-2002, no entanto, desde 1962 existe uma lei de repressão ao abuso do poder econômico (lei 4.137/62), que criou o CADE (Conselho Administrativo de Defesa Econômica). Somente em 11/06/1994 foi promulgada a lei 8.884 que deu os passos decisivos para a constituição de um aparato de defesa da concorrência no país, transformando o CADE em autarquia vinculada ao Ministério da Justiça através desta Lei.

A legislação de defesa da concorrência, ou antitruste, em sua denominação original exerce duas funções básicas:

- Coibir o abuso do poder econômico;

- Prevenir a concentração do poder de mercado.

A política de defesa da concorrência procura dessa forma preservar uma espécie de "patrimônio da sociedade". Trata-se de um direito difuso, ou seja, que pertence à coletividade como um todo. (Leopardi Mello, 2002).

No Brasil, o contrato de concessão é o lastro da regulação, sendo ele um instrumento complexo que possui dois objetivos com potencial de conflito: maximizar o bem-estar do consumidor e garantir um retorno atrativo para o investidor. 
No caso brasileiro das telecomunicações, o argumento colocado a favor da necessidade de regulamentação ou o discurso sobre a defasagem da mesma diante do avanço das inovações tecnológicas, tem resultado improdutivo, na medida em que estão ocorrendo reduções significativas dos custos mínimos e da escala mínima ótima de produção, aumentando consideravelmente a concorrência neste mercado.

O fato da melhora no aspecto concorrencial per si não seria o único argumento para justificar que não há necessidade de regular, dado que o setor de telecomunicações tem aspectos estratégicos que precisam ser outorgados pelo poder concedente para que se alcance os resultados almejados.

As grandes perguntas em questão são: por que termos uma regulação em telecomunicações? A regulação econômica é eficiente e eficaz em qual(is) contexto(s) histórico(s)? O objetivo do estudo é responder não apenas analisando esta questão, mas apresentando todo o contexto onde ela está inserida. Ou seja, os motivos que levam os Estados à regulação econômica em geral, e se suas ações têm o reflexo desejado apesar do anacronismo entre as leis e à evolução do mercado segundo alguns autores.

\section{Evolução do setor de telecomunicação no brasil: privatização e regulação}

Há 40 anos uma série de transformações deu início à era das telecomunicações e prosseguiram em direção à era da convergência digital (o processo de inovações tecnológicas da indústria de telecomunicações tem impacto/reflexo muito grande em todo processo produtivo).

Em 1969 uma linha de telefone fixo custava aproximadamente US\$ 5.000, e apenas se utilizava para o serviço de voz. Hoje, esta é uma pequena parcela do fluxo de dados e informações que as inovações tecnológicas permitem trafegar através das redes de telefonia através de bites e bytes.

Telefones fixos, celulares, televisores, computadores e outros aparelhos multifuncionais permitem através da Internet ou de redes wireless o tráfego de informações e a interação contínua e crescente entre todos, originando daí o conceito de Internet das Coisas (do inglês, Internet of Things ou simplesmente "IoT", é uma rede de objetos físicos, veículos, prédios e outros que possuem tecnologia embarcada, sensores e conexão com rede capaz de coletar e transmitir dados) (SANTOS, BRUNO P. et al. 2016).

A reestruturação do setor de telecomunicações brasileiro iniciou-se com o processo de privatização do Sistema Telebrás, que era um monopólio estatal verticalmente integrado e organizado em diversas subsidiárias, as quais prestavam serviços em uma rede de telecomunicações interligada por todo território nacional.

O processo de privatização iniciado na década de 80 teve seu auge na década de 90 com o lançamento do PND (Plano Nacional de Desestatização), tornando este processo uma prioridade do governo Fernando Henrique Cardoso, que buscava modernizar e reestruturar o papel do Estado e da economia como um todo, com a liberalização e a desregulamentação do mercado doméstico.

O processo de reestruturação do setor de telecomunicações brasileiro mostrou que a existência de um sistema regulador eficiente tornar-se-ia imperiosa à medida que o processo de privatização alcançasse a prestação de serviços de utilidade pública como o de telecomunicações. 
Enfim, em 1995 ocorreram importantes reestruturações nos setores de infraestrutura e mudanças constitucionais que culminaram com a criação da agência reguladora de energia elétrica ANEEL em 1996, ou seja, o processo começou dois anos antes da criação da ANATEL.

\section{A reforma do modelo: processo de privatização e consequências estruturais}

A reforma estrutural do modelo de telecomunicações brasileiro partiu da constatação de que o modelo vigente até então não atendia às necessidades de crescimento do país e não correspondia a padrões semelhantes na realidade mundial. $\mathrm{O}$ modelo era essencialmente monopolista e não diversificado, não acompanhando o período de globalização da economia, tão pouco a evolução tecnológica e a rapidez das mudanças no mercado e as necessidades dos consumidores.

Foram estabelecidas metas de expansão do sistema de telecomunicações com base nestes objetivos, visando ampliar a oferta de acessos aos diferentes serviços. Essas metas foram descritas no PASTE Programa de Recuperação e Ampliação do Sistema de Telecomunicações e do Sistema Postal, e foram divulgadas pelo Ministério das Comunicações no final de setembro de 1995.

Com respeito aos objetivos de universalização e qualidade - indicadores estes encontrados no PASTE eles compreendiam as perspectivas de expansão e modernização do Setor de Telecomunicações da Anatel. Os mais importantes são ligados ao Plano Geral de Metas para Universalização (PGMU) e ao Plano Geral de Metas de Qualidade (PGMQ), ambos do Sistema de Telefonia Fixa e Comutada.

Logo antes da privatização da Telebrás, em abril de 1998, foi lançado o Plano Geral de Outorgas (PGO), que definiu os parâmetros gerais para a competição e as novas regras para a abertura do mercado de telecomunicações, incluindo as diferentes áreas geográficas para a exploração dos novos serviços.

$\mathrm{O}$ fato é que o atendimento dos indicadores, assim como do cronograma de abertura do mercado, previsto no PGO, representaram uma enorme mudança e determinaram, juntamente com a disponibilidade de fontes internas de recursos, a abertura do mercado brasileiro de telecomunicações.

A ANATEL foi criada como uma autarquia especial ligada ao Ministério das Comunicações, constituída com características que lhe permitissem desempenhar a sua missão com autonomia e independência, sendo que seus dirigentes gozariam de estabilidade, e que a instituição teria autonomia decisória e orçamentária previamente concedida através da LGT, regulamentada pelo Decreto 2.238/97.

Podemos resumir como principais atributos da ANATEL: regular, outorgar e fiscalizar.

A existência da ANATEL e da regulamentação do mercado de telecomunicações também tinha como objetivo gerar um ambiente de estabilidade regulatória que viabilizaria no longo prazo investimento no setor. Essa seria a peça-chave para inspirar a confiança dos investidores na estabilidade do mercado, do contrário, a ausência de competência técnica e de independência decisória geraria desconfiança e como consequência afastaria os investidores.

Houve considerável avanço em quase todos os indicadores referentes à qualidade, com os resultados relevantes a acessos superando todas as previsões da Anatel nesta primeira etapa. Já em fins de 1999, a maioria dos indicadores já mostrava que as metas de qualidade haviam sido atingidas e, logo, todos os 
objetivos estariam cumpridos.

\section{Atributos da regulação em função da mudança estrutural ocorrida}

A presença de inovações tecnológicas criou condições importantes para modificações no regime regulatório dos setores de infraestrutura em geral, e em particular no segmento de telecomunicações, com a finalidade de aumentar a competição e permitir maior desregulamentação no segmento.

O objetivo da regulação econômica é aumentar o bem-estar e a eficiência econômica nos segmentos regulados, sempre com foco no aspecto das inovações tecnológicas, onde há uma grande contribuição para redução da escala mínima necessária ao fornecimento de diversos serviços de infraestrutura, adicionando ainda à pressão da demanda por maior customização de serviços. (PIRES \& PICCININI, 1999).

Um dos motivos que pode ser levantado como fundamental para que este movimento seja visto com bons olhos é justamente a constatação de que há ineficiências regulatórias no controle de empresas privadas, tendo em vista que o processo regulatório envolve pesados custos orçamentários, e muita das vezes decisões ineficientes devido à rigidez e ao atraso decisório ocasionado pelo modelo burocrático do Estado, além do já mencionado risco de captura das agências reguladoras pelas empresas concessionárias (Schwartz, 1997).

$\mathrm{Na}$ atualidade, existem duas tendências que objetivam superar os problemas que foram mencionados anteriormente: introdução de mecanismos de incentivo e a intervenção regulatória indireta.

A introdução de mecanismos de incentivo tem a finalidade de encorajar as operadoras ou os segmentos que ainda atuam como monopólios naturais a atingir objetivos similares aos observáveis em situação de competição nos mercados, já a intervenção regulatória indireta atuava por meio do estímulo e do monitoramento de uma estrutura competitiva para a indústria, com a finalidade de criar o ambiente mais neutro possível para todos os agentes envolvidos.

Resumindo, a eficácia da regulação é atingida quando se dispõe de diversos instrumentos como: existência de agências independentes, controle da entrada e saída do mercado (através de licenças para as operadoras), defesa da concorrência, definição do valor e do critério de revisão de reajuste tarifário (utilizando-se de mecanismos que permitam medir a eficiência), monitoramento dos contratos de concessão (objetivando avaliar a qualidade dos serviços prestados e de universalização do atendimento).

Para que o papel de regulação possa ser exercido com ideal eficácia pela reguladora, é necessário que determinados instrumentos estejam disponíveis para isso, a saber:

1. Agências independentes;

2. Controle de entrada e saída;

3. Regulação da concorrência.

Segundo explica a captura regulatória, a regulação econômica visa corrigir falhas de mercado, e o papel principal do regulador é de ser o árbitro de interesses contraditórios. 
Entretanto, sua ação é sujeita a influência dos grupos afetados, que frequentemente têm uma relação de troca com quem promove a regulação (seja através de apoio político ou através de recursos).

Segundo diz a Teoria da Captura, há captura do legislador quando o aparato regulatório criado deixa de atender ao objetivo do ótimo social para atender a demanda por regulação da indústria e do regulador, sendo que a agência passa a atender aos interesses da indústria com o tempo.

Argumenta-se que ela não explica como a indústria controla a regulação, no entanto, conforme esclarecem as Teorias da Escolha Pública, que aplicam os princípios do "individualismo metodológico" à esfera política, conclui-se que os políticos e os administradores do Estado são incitados a trabalharem em prol de seus próprios interesses em detrimento de objetivos coletivos pelos quais deveriam trabalhar, conforme afirma James Buchanan.

Esse argumento levanta o paradoxo de que o objetivo da regulação econômica de atingir o ótimo social, através da intervenção do Estado na economia (welfare economics), e desta forma buscar o equilíbrio de mercado (na falta de alternativa melhor), leva a "fracassos de governo", demonstrando que há limites na intervenção deste mesmo Estado na economia.

Dentre as responsabilidades da ANATEL, e a finalidade da regulamentação do mercado de telecomunicações, está a de gerar um ambiente de estabilidade regulatória que viabilizaria no longo prazo o investimento no setor. Sem isso a reforma não inspiraria confiança aos investidores de que há estabilidade do mercado, pois, do contrário, a ausência de competência técnica e de independência decisória geraria desconfiança e, como consequência, afastaria os investidores.

A mudança circunstancial do marco regulatório, visando atender interesses do Estado gera impacto negativo ao incentivo ex-ante aos investimentos de novos possíveis entrantes, ou seja, mudanças do marco regulatório indicam que "as regras sempre podem mudar quando for conveniente".

O papel de instigador da concorrência de mercado através do papel regulador é contraditório com a eliminação de um concorrente potencial, reduzindo a contestabilidade do mercado, que poderia ser gerada por uma possível política regulatória de acesso a redes.

Apesar dos avanços do modelo adotado no Brasil, o mesmo carece de mecanismos pró-concorrenciais, de transparência e estabilidade nas regras do mercado, de forma a gerar incentivos para que as falhas de mercado sejam corrigidas, minimizando ou evitando possíveis falhas de governo.

O papel da ANATEL é estratégico, e cabe a ela agir antecipando movimentos do mercado, de forma preventiva, e implementando instrumentos concorrenciais, dado que seu escopo é amplo.

\section{Desempenho das telecons no pós-privatização}

O setor de telecomunicações no Brasil sofreu uma evolução significativa em relação ao panorama existente no período pré-privatização onde o sistema era estatal e inadequado aos padrões de crescimento desejáveis para o país, e de qualidade e características inferiores ao panorama mundial do segmento.

Entre 2001 e 2006, as empresas de telecomunicações realizaram o maior plano de investimentos visando 
à expansão, modernização e melhoria na qualidade da prestação dos serviços prestados.

Certamente não se pode dizer isso sem o devido incentivo que a regulação econômica deu início através dos diversos instrumentos que ela dispunha para primeiramente aumentar a penetração da telefonia móvel e fixa nos domicílios, e posteriormente garantir o crescimento indispensável para modernização do parque industrial brasileiro.

Após período de desenvolvimento no Brasil, no qual a universalização do serviço de telefonia fixa foi o carro-chefe, as operadoras começaram a focar nos serviços que oferecessem maior valor agregado ao seu produto.

No final de 2010, o Brasil já contava com 202,9 milhões de acessos do Serviço Móvel Pessoal (SMP), tendo registrado crescimento de $16,7 \%$ em relação ao ano anterior. A estimativa para o final do ano de 2011 é de chegarmos a 235 milhões de acesso. Já com o resultado de fechamento de 2010, o país alcançou o quinto lugar no ranking mundial de acessos da telefonia móvel, ficando atrás, apenas, de China, Índia, Estados Unidos e Rússia, conforme levantamento realizado pela International Telecommunication Union em 222 países.

Essa evolução foi causada, em grande parte, pelo uso cada vez maior de novas funcionalidades, como, por exemplo, os terminais dedicados a conexões de dados.

Desse total de acessos de SMP em 2010, 82,3\% eram pré-pagos e 17,7\%, pós-pagos. A quantidade de prépagos no Brasil deve-se, principalmente, à possibilidade de controle de gastos que possibilitam à maioria da população, em especial à de baixa renda consumir um limite determinado de créditos de acordo com seu orçamento.

No final de 2010, estavam em andamento na Anatel diversas iniciativas para reduzir os preços cobrados na modalidade pré-paga, como a contratação de consultoria para a construção de um Modelo de Custos, conforme divulgado pelo Relatório Anual de 2010.

No entanto, apesar de ocorrerem sucessivos esforços das operadoras para buscarem ampliação de marketshare, o pré-pago permanece como a modalidade mais cara em relação ao pós-pago. O principal fator de oneração do serviço de telefonia móvel certamente está vinculado à carga tributária, que segundo dados levantados pela Telebrasil - SINDITELEBRASIL, até 2005, correspondia a 40,2\%. 


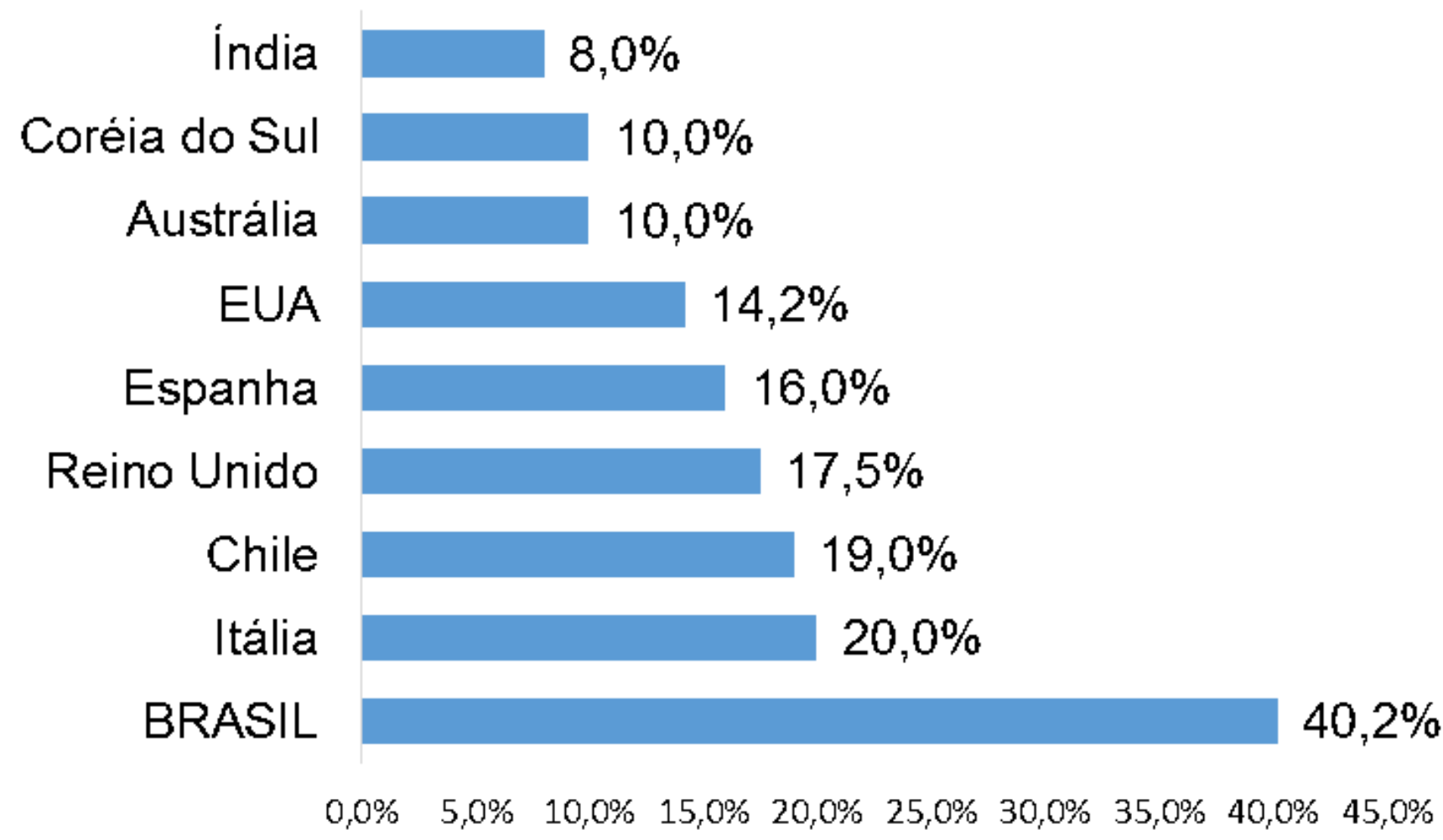

GRÁFICO - Carga de Impostos sobre os serviços de telecomunicações (em \%). Fonte: Material elaborado por Telebrasil -Sinditelebrasil, janeiro/2006

Esta é a maior carga tributária do mundo (mais que o dobro do segundo colocado conforme gráfico acima) incidente sobre o valor pago pelo usuário de serviços de telecomunicações. Em 2010, os tributos atingiram a mais alta taxa da história em um ano: 41,8\% incidente sobre o valor tarifado pelo serviço prestado, conforme dados da Telebrasil.

\section{Conclusão}

A regulação é efetiva quando alcança o que almeja, devendo também buscar ser eficiente e responsável. Isso significa que ela serve para alcançar objetivos bem estabelecidos e que não impõe cargas e custos desnecessários para a sociedade como um todo, reduzindo assim a discricionariedade e a captura do consumidor pelo regulado, assim como do regulador pelo regulado. Sendo ainda, aberta, participativa e clara em sua preparação e implementação do processo competitivo.

Tudo isso tem inúmeras vantagens, entre elas: dar segurança ao sistema regulatório, reduzir riscos e custos intrínsecos do sistema, ampliar a participação e o controle social e promover o desenvolvimento e o crescimento econômico.

O presente trabalho vem demonstrar como é fundamental a adoção de políticas públicas que venham acompanhadas de uma legislação e de um marco regulatório capazes de criar condições que incentivem as empresas a realizarem esses investimentos, garantir ao investidor a justa e adequada remuneração, e promover o desenvolvimento indispensável à infraestrutura do segmento no país. 
É essencial ainda assegurar a estabilidade regulatória e a flexibilidade necessária para que o investidor possa gerir seu negócio da forma que melhor se ajuste ao mercado em que ele atua, e no caso específico do trabalho apresentado, no mercado de telecomunicações brasileiro.

O avanço que ocorreu desde a década de 90 foi demonstrado através de dados categóricos quanto aos acertos do modelo adotado, e como foi possível comprovar os serviços atenderam de forma razoável no que tange à aspectos de quantidade, diversidade e cobertura. Contudo, aspectos como qualidade dos serviços prestados e finais precisam progredir para que o consumidor perceba a evolução em todos os sentidos.

A dificuldade de se valer de regras claras, assumidas ex-ante pelo regulador, foi o obstáculo encontrado pela regulação econômica através do modelo adotado no Brasil, isso se deve a fatos inerentes às características do Estado, que é extremamente sujeito a interferências, e onde as ações são motivadas por decisões que a teoria da escolha pública analisa, e classifica como falhas de governo, as quais são associadas à possíveis falhas de eficiência econômica das decisões e à injustiça na repartição do rendimento.

Em um ambiente extremamente dinâmico e essencial como o das telecomunicações, onde os cidadãos, as empresas e o próprio governo tornaram-se extremamente dependentes da prestação dos serviços, observase a necessidade de uma evolução permanente da legislação e da regulamentação de forma à acompanhar o crescimento do setor.

O aspecto da qualidade, certamente é ligado a iniciativas compatíveis de investimento, buscando a melhoria e o acesso universal do serviço em todas as camadas de consumidores, onde o montante que foi investido no início do processo de privatização terá de ser novamente aplicado nos próximos anos para alcançar as melhorias necessárias no segmento.

Quanto ao preço da disponibilidade dos serviços para o consumidor, podemos identificar através dos estudos realizados por Turolla e Freire de Lima (2008) que ainda há significativas melhorias a serem alcançadas, e existem diversos mecanismos que permitem isso.

A argumentação de que determinadas decisões são tomadas com finalidades de atender a interesses públicos, conforme demonstrado no estudo de caso, necessita do aprofundamento das decisões, sob a ótica da regulação econômica, visando identificar todas as externalidades associadas à operação, antes da aprovação.

Não julgamos com isso, que o ferramental e o conhecimento não estejam disponíveis no âmbito técnico dos reguladores e dos policy makers, contudo, conforme observado por diversos economistas (Wicksell, Buchanan e outros), "a perspectiva da teoria da escolha pública é que as decisões políticas e (sobretudo) econômicas (...) estão sujeitas a um conjunto de poderes repartidos por diferentes agentes com funções (e interesses) diferentes no sistema político" (Pereira, 2002).

Apenas observamos que o princípio da melhor escolha, onde todos os indivíduos envolvidos melhoram de situação, ou seja, melhoramentos de Pareto onde os recursos alocados atingem "jogos de soma zero" dependem de regras claras para ser alcançado. 
Outro aspecto que deve ser levado em consideração no papel de redistribuição que o governo e os agentes reguladores exercem, é o de realocar os recursos visando que os “jogos sejam de soma zero", no entanto, via de regra a análise é econômica e a decisão é política, onde impera o homo economicus que age, por vezes, através do egoísmo e da irracionalidade nas escolhas.

Como projeto de pesquisa a ser seguido posteriormente, destacam-se as seguintes questões:

1. Poderia o controle das empresas através da aplicação de normas proibitivas de certas condutas lesivas da concorrência (os acordos, práticas concertadas entre empresas e as decisões de associações de empresas, além de práticas unilaterais de empresas que disponham de um poder de mercado significativo) melhorar as condições de regulação no Brasil?;

2. Como reforçar o papel do Sistema Brasileiro de Defesa da Concorrência (CADE, SAE e Anatel), impedindo que haja captura do regulador pelo regulado, assim como do regulador pelo Estado, que age de forma a atender interesses diferentes do ótimo social?

Algumas receitas concorrenciais deste segmento são conhecidas: abertura de redes locais; separação funcional de estruturas que promovam práticas anticompetitivas, desinvestimento/proibição da prestação de serviços concorrentes em redes sobrepostas, convergência da legislação aproximando-a das novas possibilidades que o mercado apresenta (convergência de serviços pede convergência da legislação).

Além disso, outros aspectos pró-competitivos podem ser outorgados visando o desenvolvimento econômico e da infraestrutura do país, tendo como contrapartida utilização dos impostos recolhidos do segmento: aumento do investimento em P\&D, obrigação de universalização, contrapartida de nacionalização de serviços e insumos visando crescimento do parque tecnológico, "upgrade" das redes em regiões menos rentáveis, abertura de mercados das regiões com menor concorrência.

\section{Referências}

ANDRADE, Maria Margarida de. Introdução à Metodologia do Trabalho Científico: Elaboração de Trabalhos na Graduação. 5 Ed. São Paulo. Editora: Atlas, 2001.

FIANI, Ronaldo. Teoria dos jogos - Estratégias Em Negócios, Economia e Política - 2a Edição. Editora: Campus, 2007

GIAMBIAGI, Fábio; ALÉM, Ana Cláudia de. Finanças públicas: teoria e prática no Brasil, - O Estado Regulador, 2a edição: Editora Campus, 2001.

GUJARATI, Damodar. Econometria Básica. $3^{\text {a }}$ Edição: Editora: Makron Books, 2000.

HILL, R. Carter; GRIFFITHS, Willam E.; JUDGE, George G.. Econometria. $2^{a}$ edição. Editora Saraiva, 2006.

KUPFER, David; HASENCLEVER, Lia, (organizadores). Economia industrial - fundamentos teóricos e práticas no Brasil. Rio: Campus, 2002

MEDEIROS, Valeria Zuma. Métodos Quantitativos Com Excel. Edição: 1ª Editora: Cengage Learning, 
2009.

VILLELA, A.;GIAMBIAGI, F.; CASTRO, B.C.; e HERMANN, J. (orgs. ) Economia Brasileira Contemporânea (1945-2004). São Paulo: Campus, 2004.

Glossário

de

Telecomunicações.

Disponível

em:

<http://www.abrafix.org.br/admin/imagens/upload/dados_setor_arquivos/glossario.pdf>. Acesso 20 jul. 2011.

Estudo Técnico para Atualização da Regulamentação das Telecomunicações no Brasil. 2008. Disponível em: <http://www.anatel.gov.br/Portal/exibirPortalInternet.do>. Acesso 15 jan. 2011.

Plano Geral para Atualização da Regulamentação no Brasil - 2008. Disponível em: < http://convergenciadigital.uol.com.br/inf/pgr.pdf>. Acesso 15 abr. 2010.

Relatório Anual ANATEL - 2008, 2009 e 2010. Disponível em: <http://www.anatel.gov.br/Portal/exibirPortalInternet.do>. Acesso 15 jan. 2011.

Concentração de Mercado do SMP. Disponível em: <http://www.anatel.gov.br/Portal/verificaDocumento s/documento.asp?numeroPublicacao $=262166 \&$ assuntoPublicacao $=\mathrm{CONCENTRA} \% \mathrm{C} 7 \% \mathrm{C} 3 \mathrm{O} \% 20 \mathrm{DO} \% 2$ 0MERCADO\%20DE\%20SMP\%20(INDICE\%20HERFINDAHLHIRSCHMAN)\&caminhoRel=null\&filt ro=1\&documentoPath=262166.pdf $>$. Acesso 06/04/2012.

ARCULUS, David and SALOMON, Eve. Routes to Better Regulation. Better Regulation Task Force. December 2005. Disponível em: <http://www.regulacao.gov.br/publicacoes/artigos/regulating-better-agovernmentwhite-paper-setting-out-six-principles-of-better-regulation>. Acesso 01 jan. 2009.

Cadernos de Infraestrutura, As Telecomunicações no Brasil. Junho/2000. Disponível em: <http://www.bn des.gov.br/SiteBNDES/export/sites/default/bndes_pt/Galerias/Arquivos/conhecimento/cadernos/cad015.p df>. Acesso 30 jan. 2011.

CAMPOS, Humberto Alves de. Falhas de mercado e falhas de governo: uma revisão da literatura sobre regulação econômica. 2009. Disponível em: <http://www.regulacao.gov.br/publicacoes/artigos/prismasregulacao-economica>. Acesso 01 fev. 2010.

CARNEIRO, Maria Christina Fontainha e BORGES, Luiz Ferreira Xavier. Financiamento das Telecomunicações no Brasil: Balanço e Perspectivas. Revista do BNDES, Rio De Janeiro, V. 9, N. 17, P. 153-168, JUN. 2002. Disponível em: <http://www.bndes.gov.br/SiteBNDES/bndes/bndes_pt/Institucional /Publicacoes/Consulta_Expressa/Setor/Telecomunicacoes/200206_8.html>. Acesso 30 jan. 2011.

CHAMBEL, Carlos. A Regulação Econômica dos Monopólios Naturais. Disponível em: <http://in3.dem.ist.utl.pt/master/02energy/pres5.pps>. Acesso 1 mar. 2010.

COELHO, Daniel Simões; CARVALHO, David Sacramento. Jean Baptiste Say e a regulação econômica. 2009. Disponível em: <http://intl.feedfury.com/content/36940633-jean-baptiste-say-e-a-regula-oeconmica.html>. Acesso 15 abr. 2010. 
COSTA, Luciano. É Mesmo Necessário Regular Telecomunicações?. Disponível em: <http://www.teleco.com.br/legis_forum/lucianocosta09.asp>. Acesso 15 jan.2011.

DA SILVA, Antonio Carlos Valente. Evolução do mercado de telecomunicações do Brasil, pósprivatização. Abril/2000. Disponivel em: <http://www.bndes.gov.br/SiteBNDES/bndes/bndes_pt/Instituci onal/Publicacoes/Consulta_Expressa/Setor/Telecomunicacoes/200002_15.html>. Acesso 15 mar. 2010.

DA SILVA, José Luiz Toro. A polêmica sobre as Agências Reguladoras. Disponível em: <http://www.dir eitodoestado.com.br/noticias/4515/Apol\%C3\%AAmica-sobre-as-Ag\%C3\%AAncias-Reguladoras .

21/08/2007. Acesso 1abr. 2010.

DRUCK, Graça - A teoria da regulação transforma-se em "técnica de regulação" em tempos neoliberais? Disponível em: <www.scielo.br/pdf/rbcsoc/v20n57/a11v2057.pdf>. Acesso 15 mar. 2010.

ECONOMIDES, Nicholas. Telecommunications Regulation: An Introduction. Revised June 2004. Disponível em: <http://ssrn.com/abstract=465020 or doi:10.2139/ssrn.465020>. Acesso 15 fev. 2010.

FIANI, R. Afinal, a quais interesses serve a regulação? Economia e Sociedade, Campinas, v. 13, $\mathrm{n}^{\circ} 2$ (23), 2004 p.81-105. Disponível em: <http://www.eco.unicamp.br/docdownload/publicacoes/instituto/revi stas/economia-esociedade/V13-F2-S23/Fiani.pdf> . Acesso 15 abr. 2010.

FIANI, R. Teoria da Regulação econômica: estado atual e perspectivas futuras. Finep, 2004 (pdf). Disponível em: <www.ie.ufrj.br/grc/pdfs/teoria_da_regulacao_economica.pdf>. Acesso 15 mar.2010.

FIANI, Ronaldo. Tendências da Regulação Econômica no Caso Brasileiro: Uma Reflexão a Partir do Debate Internacional. 2002. Disponível em: <http://www.ie.ufrj.br/revista/pdfs/tendencias_da_regulacao_ economica_no_caso_brasileiro_uma_reflexao_a_partir_do_debate_internacional.pdf $>$. Acesso 01 fev. 2010.

FRANCHINI, Alinne A. e CASTRO, Gilmar Pinheiro Cunha. A Teoria Da Regulação: Uma Revisão. UFV/MG. 2004. Disponível em:<http://www.viannajr.edu.br/revista/eco/doc/artigo_40002.pdf >. Acesso 01 dez.2009.

GIFONI NETO, Gontran. Instituições Regulatórias Do Transporte Rodoviário Intermunicipal De Passageiros: O Caso Das Agências Reguladoras Estaduais Brasileiras. 2002. Disponível em: <www.det.ufc.br/index.php?option=com_docman\&task=doc...26...>. Acesso 01 dez.2009.

GONÇALVES, Pedro. Regulação das Telecomunicações. Faculdade de Coimbra. Novembro de 2002. Disponível em: <http://www2.eptic.com.br/sgw/data/bib/artigos/7cd6eed8876a6c6f2c4e6db844248d79.pdf>. Acesso 01 jan. 2009.

GROTTI, Dinorá Adelaide Musetti. As agências reguladoras. Revista Eletrônica de Direito Administrativo Econômico, número 6, maio/junho/julho 2006. Disponível em: <http://www.direitodoestado.com/revista/redae-6-maio-2006-dinora.pdf >. Acesso 1mar. 2010. 
GUIMARÃES, Denis Alves e FARINA, Laércio. A Reforma Do Cade E As Agências Reguladoras. 09/2009. Disponível em:<http://www.regulacao.gov.br/publicacoes/artigos/a-reforma-do-cade-e-asagenciasreguladoras>. Acesso 01 fev. 2010.

HOWE, Charles W. The Effects Of Privatization Of Public Services: The Case Of Urban Water. University of Colorado at Boulder. Disponível em: 〈http://www.ucowr.org/updates/pdf/V117_A9.pdf>. Acesso 03/2012

KUJAWSKI, Fabio Ferreira; SELLAN, Piero Augusto, GENTIL, Thays Castaldi Políticas Públicas e Regulação. 03/2010. Disponível em: <WWW.teleco.com.br>. Acesso 15 fev. 2011.

LOURAL, Claudio de Almeida; LEAL, Rodrigo Lima Verde. Desafios e Oportunidades do Setor de Telecomunicações no Brasil. Textos para Discussão CEPAL-IPEA. Setembro/2010. Disponível em: <http ://agencia.ipea.gov.br/index.php?option=com_content\&view=article\&id=1378:estudo-apresentapanorama-brasileiro-da-telecomunicacao\&catid=9:diset\&Itemid=8> . Acesso 15 mar. 2011.

LOYOLA, Gustavo. Regulação tupiniquim é contra os mercados. Valor Econômico, São Paulo, 12 dezembro 2005. Disponível em: http://www.valoronline.com.br/veconomico/colunistas/?show=index\&m $\mathrm{at}=3431425 \&$ caderno $=$ col\&edicao $=1243$. Acesso em: $01 \mathrm{dez} .2010$

MATTOS, César e MUELLER, Bernardo. Regulando o Regulador: A Proposta do Governo e a ANATEL. 2007. Disponível em: <www.ppge.ufrgs.br/giacomo/arquivos/.../mattos-mueller-2006.pdf>. Acesso 01 jan.2009.

MATTOS, Paulo T. L. O novo Estado regulador no Brasil: eficiência e legitimidade. SP: Singular, 2006. Capítulo $3 . \quad$ Disponível em: <http://academico.direitorio.fgv.br/ccmw/images/0/0b/CAP\%C3\%8DTULO_3_-_Paulo_Mattos.pdf>. Acesso 30 abr. 2010.

MATTOS, Paulo Todescan Lessa. A formação do Estado regulador. Revista Novos Estudos Cebrap, nov. 2006.

Disponível em:<http://www.scielo.br/scielo.php?pid=S0101-33002006000300007\&script=sci_arttext $>$. Acesso 30 abr. 2010.

NEVES, Mauricio dos Santos. O Setor De Telecomunicações. Caderno Setorial 13,

07/2003. Disponível em: <http://www.bndes.gov.br/SiteBNDES/bndes/bndes_pt/Institucional/Publicacoe s/Consulta_Expressa/Setor/Telecomunicacoes/200212_8.html >. Acesso 15 fev. 2011.

F. A regulação econômica no quadro da desestatização. (conferência) - Congresso da Sociedade de Estudos Jurídicos Brasil- Alemanha. (pdf). Disponivel em: <www.fea.pucsp.br/1_semestre_2010/inovacao.html>. Acesso 30 abr. 2010.

OLIVEIRA, Gesner de. Regulação Pró-Concorrencial E O Novo Ciclo De Abertura Comercial No Brasil. Texto Para Discussão 132 - Fevereiro De 2004. Disponível em: < http://bibliotecadigital.fgv.br/dspace/handle/10438/1931> . Acesso 15 jan. 2011. 
PECI, Alketa. Reforma Regulatória Brasileira dos Anos 90 à Luz do Modelo de Kleber Nascimento. RAC, v. 11, n. 1, Jan./Mar. 2007. Disponível em: <http://www.anpad.org.br/periodicos/arq_pdf/a_102.pdf>. Acesso 15 fev. 2011.

PEREIRA, Paulo T. Teoria da Escolha Pública (public choice): uma análise económica do processo político. 2002.

Disponível em: <http://analisesocial.ics.ul.pt/documentos/1221841484T5sAW2pw7Dh10FX8.pdf >. Acesso: 15 fev. 2011

PINTO Jr., Helder Q. e PIRES, Melissa Cristina Pinto. Assimetria De Informações E Problemas Regulatórios. Fevereiro/2000. Disponível em: <http://www.ppge.ufrgs.br/giacomo/arquivos/eco02036/pintojr-pires-2000.pdf>. Acesso 15 fev. 2011.

PIRES, José Claudio Linhares e DAS DORES, Adely Branquinho. Fusões e Aquisições no Setor de Telecomunicações: Características e Enfoque Regulatório. Revista do BNDES, Rio De Janeiro, V. 7, N. 14, P. 179-228, Dez. 2000. Disponível em: <http://www.bndes.gov.br/SiteBNDES/bndes/bndes_pt/Institu cional/Publicacoes/Consulta_Expressa/Setor/Telecomunicacoes/200010_1.html>. Acesso 31 mar. 2010.

PIRES, Jose Claudio Linhares e PICCININI, Maurício Serrão. A Regulação dos Setores de Infraestrutura no Brasil. páginas 217 à 258, Revista BNDES (1999). Disponível em: <http://www.bndes.gov.br/SiteBN DES/export/sites/default/bndes_pt/Galerias/Arquivos/conhecimento/livro/eco90_07.pdf > . Acesso 1 maio. 2010.

PIRES, Jose Claudio Linhares. A Reestruturação do Setor de Telecomunicações no Brasil, in Políticas Regulatórias no Setor de Telecomunicações: A Experiência Internacional e o Caso Brasileiro. 2002. Disponível em: <http://www.bndespar.com.br/SiteBNDES/export/sites/default/bndes_pt/Galerias/Arquiv os/conhecimento/revista/rev1109.pdf >. Acesso 15 maio. 2010.

POSSAS, Mario; FAGUNDES, Jorge e PONDÉ, João Luiz. Defesa da Concorrência e regulação de Setores de Infraestrutura em transição. Agosto/2004. Disponível em: <http://www.ie.ufrj.br/grc/pdfs/defe sa_da_concorrencia\%20e_regulacao_de_setores_de_infra_estrutura_em_transicao.pdf $>$. Acesso 15 fev. 2011.

SALGADO, Lucia Helena. Agências Regulatórias Na Experiência Brasileira: Um Panorama Do Atual Desenho Institucional. Março/2003. IPEA, Texto para Discussão. Disponível em: < http://www.ipea.gov.br/pub/td/2003/td_0941.pdf>. Acesso 01 fev. 2010.

SAMPAIO, Elias. Teoria da regulação e abordagem neo-shumpeteriana: algumas reflexões sobre a possibilidade de complementaridade e convergência teórica. 2003. Disponível em: <www.anpec.org.br/encontro2003/artigos/A28.pdf>. Acesso 1 mar. 2010.

SANTOS, Luiz Alberto. Eficiência e eficácia de sistemas de regulação: o caso brasileiro. X Congresso Internacional del CLAD sobre la Reforma del Estado y de la Administración Pública, Santiago, Chile, 18 - $21 . \quad$ Outubro/2005. Disponível em: <www.bresserpereira.org.br/Documents/MARE/Agencias/santos_reg.pdf>. Acesso 01 dez. 2009. 
SCHUMPETER, J. Teoria do desenvolvimento econômico. SP: Abril, 1982. (cap.2). Disponível em: < ftp://ftp.sp.gov.br/ftpiea/tec3-0894.pdf>. Acesso 30 abr. 2010.

SOUZA, José Antonio de. Privatização: Os Impactos no Setor de Telecomunicações Brasileiro. 01/2008. Disponível em: <WWW.teleco.com.br>. Acesso 15 mar. 2011.

SPENCE, David B. and GOPALAKRISHNAN, Lekha. Bargaining Theory and Regulatory Reform: The Political Logic of Inefficient Regulation. Disponível em: <http://www.regulacao.gov.br/publicacoes/artig os/bargaining-theoryand-regulatory-reform-the-political-logic-of-inefficient-regulation/view>. Acesso 01 jan. 2009.

TAVARES, Carlos. Regulação Económica. Comissão do Mercado de Valores Mobiliários. 19 de Outubro de 2007, Faculdade de Direito da Universidade de Coimbra. Disponível em: <http://www.fd.uc.pt/cedipre/licoes_inaugurais/CEDIPRE_LicinauguralVII_DrCarlosBaptista.pdf > Acesso 15 fev. 2010.

TAVARES, Monica e ROSA, Bruno. Convergência Digital desafia telecomunicações. Disponível em: O Globo (http://oglobo.com.br/economia). Acesso 22 ago 2009.

O Desempenho do Setor de Telecomunicações no Brasil Séries Temporais - 2010. Março/2011. Disponível em: <http://www.telebrasil.org.br/Link_setor.pdf>. Acesso 30 jan. 2011.

O Setor de Telecomunicações no Brasil Uma Visão Estruturada. Novembro/2010. Disponível em: < http:/ /www.telebrasil.org.br/saibamais/O_Setor_de_Telecomunicacoes_no_Brasil_Uma_Visao_Estruturada_2 0090330.pdf>. Acesso 30 jan. 2011.

TUROLLA, Frederico Araujo; LIMA, Maria Fernanda Freire de. Análise Econômica da Concentração BrT-Oi. Pezco Pesquisa e Consultoria Ltda. Julho/2008. Disponível em: <http://www.teletime.com.br/arqs/Outro/1743.pdf>. Acesso 15 mar. 2011.

TUROLLA, Frederico Araujo; OHIRA, Thelma Harumi e FREIRE DE LIMA, Maria Fernanda. Concorrência, Convergência E Universalização No Setor De Telecomunicações No Brasil. Pezco Pesquisa \& Consultoria. Setembro/2007. Disponível em: < http://www.telcomp.org.br/site/wpcontent/upl oads/downloads/2011/12/20070913_Estudo-Converg\%C3\%AAncia_Pezco.pdf> . Acesso 15 jan. 2011.

VASCONCELOS, Raphael Carvalho de. A liberalização do setor de telecomunicações como opção política de regulação econômica. 4/11/2008. Disponível em: <http://www.ufjf.br/eticaefilosofia/files/2009/08/juri_raphaelvasconcelos.pdf>. Acesso 15 fev. 2010.

VELASCO Jr, Licinio. A privatização no Sistema BNDES. Revista do BNDES 33, junho 2010. Disponível em: <http://www.bndes.gov.br/SiteBNDES/bndes/bndes_pt/Institucional/Publicacoes/Consult a_Expressa/Setor/Privatizacao/201006_9.html >. Acesso 15 fev. 2011.

Anatel www.anatel.gov.br

http://academiaeconomica.blogspot.com/2009/07/jean-baptiste-say-e-regulacaoeconomica.html 
http://getinternet.ipea.gov.br/SobreIpea/td_1000/regu_econo_defesa_concorr.htm http://pt.wikipedia.org/wiki/Regula\%C3\%A7\%C3\%A3o_econ\%C3\%B4mica

http://www.cristinaamorim.com.br/atividade.html

http://www.ipea.gov.br

Programa de Fortalecimento da Capacidade Institucional para Gestão em Regulação

(PRO-REG) http://www.regulacao.gov.br

cade.gov.br

ibge.gov.br

${ }^{[1]}$ Mestre em Economia e Gestão Empresarial - Universidade Cândido Mendes - RJ

[2] O Teorema de Coase é uma teoria desenvolvida pelo economista Ronald Coase, que busca resolver as externalidades, existentes nos mercados. Segundo o Teorema de Coase, se os agentes envolvidos com externalidades puderem negociar (sem custos de transação) a partir de direitos de propriedade bem definidos pelo Estado, poderão negociar e chegar a um acordo em que as externalidades serão internalizadas. Adicionalmente, considerando-se preferências quase-lineares, pode-se afirmar, com base nesse teorema, que toda solução eficiente terá de ter a mesma quantidade da externalidade. (VARIAN, 2003)

\section{PUBLIQUE SEU ARTIGO CIENTÍFICO EM:}

https://www.nucleodoconhecimento.com.br/enviar-artigo-cientifico-para-submissao 